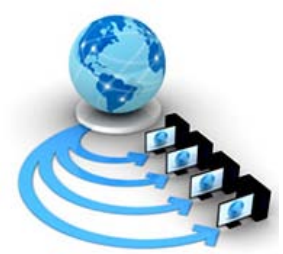

International Journal of Advanced Research in Computer Science

RESEARCH PAPER

\title{
A STUDY ON LONG TERM RAINFALL PATTERN OF DHUBRI AND GUWAHATI IN ASSAM, INDIA: A TIME SERIES APPROACH
}

\author{
A. N. Patowary ${ }^{\ddagger}$, N. Purakasthay*, K. Goswami*, P. J. Hazarika*, B. Pathak** \\ ${ }^{\sharp}$ College of Fisheries, Assam Agricultural University, Nagaon, Assam-782103, India \\ *Department of Statistics, Dibrugarh University, Dibrugarh, Assam-786004, India \\ **Department of Physics, Dibrugarh University, Dibrugarh, Assam-786004, India \\ ${ }^{q}$ Corresponding Author
}

\begin{abstract}
Understanding the rainfall pattern is tough for the solution of several regional environmental issues of water resources management, with implications for agriculture, climate change, and natural calamity such as floods and droughts. Statistical computing, modelling and forecasting meteorological data are the key instruments for studying these patterns. This study aims to establish the rainfall trends of the two stations of Assam viz. Guwahati and Dhubri. The collected data is secondary in nature and obtained from the website of Global Precipitation Climatology Project (GPCP) of NASA, Goddard Space Flight Centre, United States consisting of 36 years monthly rainfall records for the period 1979-2014. We have performed Sen's slope method and Mann-Kendall test to assess the magnitude along with the statistical significance of trend. So far as monthly analysis is concerned, a gradual decrease in rainfall has been observed for maximum months in both the stations. Moreover, seasonal analysis has witnessed a noticeable similarity between the stations that is the presence of significant downward trend for winter and monsoon months over the entire period of 1979-2014.
\end{abstract}

Keywords: Mann Kendall, Sens’ Slope

\section{INTRODUCTION}

Water is one of the most important natural resources on earth that is necessary for sustenance of all forms of life. Rainfall is one of the main sources of water in any area. The availability of water for various purposes is very much depending upon the amount of precipitation in that particular area. [10] Rainfall affects the environment and society in various ways ranging from water availability for livelihood and agriculture to the functioning of various industries, hydroelectric power generation etc. and thus affect the economy of a country like India. [1] stated that, in order to understand the hydrological balance and the complex interactions among the components within the hydrologic cycle, we need to focus on all the information regarding precipitation. Rainfall is the most important environmental factor limiting the development of semi dry regions that has less than 20 inches of rain each year. It is the meteorological phenomenon that has the greatest impact on human activities. Moreover, in order to determine the amount of water available to meet various demands such as agricultural industry, domestic water supply and for hydroelectric power supply, the rainfall received in that particular area plays an important role. Understanding rainfall variability is essential to optimally manage the scarce water resources that are under continuous stress due to the increasing water demands, increase in population and the economic development. Though, climate change is global in nature, potential changes may be consists of some dramatic regional differences. Long term rainfall patterns may get influenced by the global climatic changes and this may result with the danger of increasing the occurrences of droughts and floods. South-West monsoons have a significant impact on water resources for every sector of India as it brings nearly $80 \%$ of total rainfall in a year [12]. The climate of Brahmaputra valley cannot perhaps be discussed separately from the climate of North East India (NEI). The climate of NEI is distinct from rest of India due to special features such as orography, the altering pressure cells of NE India and that of Bay of Bangle. The region is covered by the mighty Brahmaputra Barak river systems and their tributaries. The Brahmaputra valley receives a mean annual rainfall of 2,239 $\mathrm{mm}$ [4]. Assam is the largest and the most nearby of the NE India state. The climate of Assam is typically "tropical monsoon rainfall” type with high levels of humidity and heavy rainfall. Though it has many different climates, but is dominated by cwa (the Kopper Geiger climate classification). It experiences an average rainfall of around 1,500 mm per year.

Guwahati, one of the fastest growing cities in India, is situated on the south bank of Brahmaputra river, is the largest city of Assam and North-East India, a major riverine port city. Here, total annual average precipitation is 1722 $\mathrm{mm}$. Most of the times, 2-3 hours of constant heavy rainfall causes flood in the city.

Dhubri- the gateway of Assam happened to be in the past a meeting place of different racial groups. This place is primarily dependent on agriculture and forest products. The history reveals that flood is a recurring disaster of Dhubri but presently along with flood massive erosion is occurring every year. Past study reveals that this district is one of the very high damage risk zone for flood, among all the other districts of Assam. Precipitation here averages around 2518 $\mathrm{mm}$. Climate conditions of both Guwahati and Dhubri is cwa (temperate rainy climate). All the above situations have compelled the motivation for assessing the magnitude and variability of rainfall data for Guwahati city and Dhubri stations. Statistical analysis of rainfall records for long periods is important to provide information about rainfall variability and to better manage the rain fed agricultural activities such that the impact of climate change can be assessed. 
Keeping all these points in mind, an attempt has been made to analyze the long term rainfall records of the two stations of Assam viz. Dhubri and Guwahati by time series approach. The major objective of this work is to analyze the temporal variation in annual, seasonal and monthly rainfall data for the period 1979-2014 of the two stations. In this work, we have assessed the magnitude of the trend with respect to seasons, monthly and yearly records of the two regions.

\section{STUDY AREA}

The Northeast region can be physiographically categorised into the Eastern Himalaya, the Patkai and the Brahmaputra and the Barak valley plains. NEI (at the confluence of IndoMalayan, Indo-Chinese, and Indian biogeographical realms) has a predominantly humid sub-tropical climate with hot, humid summers, severe monsoons, and mild winters. Along with the west coast of India, this region has some of the Indian sub-continent's last remaining rain forests, which support diverse flora and fauna and several crop species. Reserves of petroleum and natural gas in the region are estimated to constitute a fifth of India's total potential.

The region is covered by the mighty Brahmaputra-Barak river systems and their tributaries. Geographically, apart from the Brahmaputra, Barak and Imphal valleys and some flat lands in between the hills of Meghalaya and Tripura, the remaining two-thirds of the area is hilly terrain interspersed with valleys and plains; the altitude varies from almost sealevel to over 7,000 metres $(23,000 \mathrm{ft})$ above MSL. The region's high rainfall, averaging around 10,000 millimetres (390 in) and above, creates problems of ecosystem, high seismic activity, and floods. The states of Arunachal Pradesh and Sikkim have a montane climate with cold, snowy winters and mild summers. The southwest monsoon is responsible for bringing $90 \%$ of the annual rainfall to the region. April to late October are the months where most of the rainfall in NEI occurs with June and July being the rainiest months. Southern areas are the first to receive the monsoon (May or June) with the Brahmaputra valley and the mountainous north receiving later (later May or June). In the hilly parts of Mizoram, the closer proximity to the Bay of Bengal causes it to experience early monsoons with June being the wettest season. Brief descriptions of the two stations of Assam undertaken in this study are given below.

\subsection{Dhubri District}

Dhubri district occupies an area of 2,838 square kilometres, comparatively equivalent to Russia's Zemlya Georga. Dhubri District is bounded both by interstate and international borders: West Bengal and Bangladesh in the west; Goalpara and Bogaigoan district of Assam and Garo Hills district of Meghalaya in the east; Kokrajhar district in the north; and Bangladesh and state of Meghalaya in the south. The town had a very busy river port on the bank of the Brahmaputra, which was used as an international trade centre with the neighbouring countries, especially in British era. At present, the port is lying idle. The climate is warm and temperate in Dhubri. The summers here have a good deal of rainfall, while the winters have very little. This climate is considered to be cwa according to the KöppenGeiger climate classification. The average annual temperature is $24.2^{\circ} \mathrm{C}$ in Dhubri. Here, average precipitation is $2518 \mathrm{~mm}$.

\subsection{Guwahati City}

Guwahati straddles the valley of the river Bharalu, a small tributary of the river Brahmaputra. It is surrounded by hills, except where the Bharalu discharges into the Brahmaputra. To its west the Nilachal hill is said to be the home of the goddess Kamakhya, a shakta temple. In the past, this was an important seat of tantric and Vajrayana Buddhism. To the north, on top of Chitrachal Hill, is the Navagraha (nine planets) temple, a unique astrological temple. To the south of the city lie the Narakasur hills, named after a legendary king of ancient Assam. Guwahati today is important because it is close to the seat of power in Assam, is a commercial centre, and is the node that connects six other northeastern Indian states of Arunachal Pradesh, Nagaland, Manipur, Mizoram, Meghalaya and Tripura. The climate in Guwahati is warm and temperate. When compared with winter, the summers have much more rainfall. The Köppen-Geiger climate classification is cwa. The average annual temperature in Guwahati is $24.6^{\circ} \mathrm{C}$. The average annual rainfall is $1698 \mathrm{~mm}$.

\section{DATA AND METHODOLOGY}

Data of this study is secondary in nature. It is collected from the website of Global Precipitation Climatology Project (GPCP) of NASA, Goddard Space Flight Centre, United States. The spatial resolution of the data set is $2.5 \times 2.5$ degree and time period is 1997-2014. GPCP is an international project and the datasets are generated by aggregating rain gauge stations, geostationary, low-orbit infrared satellite, passive microwave, and sounding observations over the globe. The input datasets and techniques have been contributed to by a number of investigators [11], [2]. The finally merged product is prepared taking advantage of the strengths of each input data type and removing biases based on hierarchical relations in the stepwise approach. The microwave estimates are based on Special Sensor Microwave Imager (SSM/I) data from the Defense Meteorological Satellite Program (DMSP, United States) satellites that fly in sun-synchronous low-Earth orbits. The infrared (IR) precipitation estimates are obtained mainly from geostationary satellites operated by the United States, Europe, and Japan and secondarily from polarorbiting satellites. Additional precipitation estimates are acquired based on Television and Infrared Observation Satellite (TIROS) Operational Vertical Sounder (TOVS) and outgoing long wave radiation (OLR) measurements. Rain gauge data are collected, quality controlled, and analyzed to contribute to the analysis over land ([2] and references therein).

Time series data of annual precipitation of different parts of the world were studied statistically and trends were analysed both at annual and seasonal scale across the globe ([3]; [13]; [6] etc.). There are various statistical methods used to identify trends of hydro-meteorological time series data. Mann-Kendall (M-K) test is the most effective method among those and in this method, it is not necessary that the datasets follow normal distribution and show homogeneity in variance; transformations are not basically required if data already follows normal distribution, in skewed 
distribution greater power is achieved [5]. The MannKendall test has been commonly employed technique to detect monotonic trend in series of environmental data, climate data or hydrological data. This test has been widely used by researchers to detect trends in hydrological time series data. Mann Kendall test also discusses about function of slope in the trend, coefficient of variation, and type of probability distribution [14]. Mann-Kendall test is used for trend analysis as it eliminates the effect of serial dependence on auto-correlated data which modifies the variance in datasets [9]. In the present study, the magnitude of the trend in rainfall series is determined by using the Sen's estimator method [8]. This method has been widely used for determining the magnitude of trend in hydro-meteorological time series [12], [7]. Here, the non-parametric MannKendall test is being used to analyse the statistical significance of the trend in monthly, seasonal and annual series. In order to identify the seasonal changes in rainfall, a year is being divided into four seasons: Winter (Dec-Feb), Pre-Monsoon (March-May), Monsoon (June-Sep), PostMonsoon (Oct-Nov). The whole analysis is carried out for all the seasons, for each month separately for the period (1979-2014). Further, the entire 36 years has been subdivided into four nine year's groups for each 12 months. According to $\mathrm{M}-\mathrm{K}$ test the null hypothesis $\mathrm{H}_{0}$ states that there is no trend and the alternative hypothesis $\mathrm{H}_{1}$ states that there exists a monotonic trend (either increasing or decreasing). The MK test statistics is calculated according to

$S=\sum_{k=1}^{n-1} \sum_{j=k+1}^{n}\left(x_{j}-x_{k}\right)$

with

$\operatorname{sgn}\left(x_{j}-x_{k}\right)=\left\{\begin{array}{cc}1 \text { if } & \left(x_{j}-x_{k}\right)>0 \\ 0 & \left(x_{j}-x_{k}\right)=0 \\ -1 & \left(x_{j}-x_{k}\right)<0\end{array}\right.$

A positive value of $S$ indicates an upward trend whereas a negative value indicates a downward trend. The statistics $S$ is closely related to Kendall's $\tau$ as given by

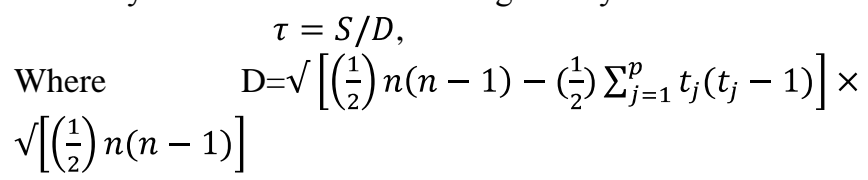

Here the magnitude of the trend in the time series was determined by using the Sen's estimator method. In this method, the slopes $\left(\mathrm{T}_{\mathrm{i}}\right)$ for all data pairs were calculated by the following way
$\mathrm{T}_{\mathrm{i}}=\frac{x_{j}-x_{k}}{j-k}$ for $\mathrm{i}=1,2 \ldots \mathrm{N}$

Here $x_{j}$ are the values at time $\mathrm{j}, x_{k}$ are the values at time $k(j>k)$. The median of these $N$ values of $\mathrm{Ti}$ is Sen's estimator of slope which is calculated as

$$
=\left\{\begin{array}{c}
T_{N+\left(\frac{1}{2}\right),} \text { if } n \text { is odd } \\
\left(\frac{1}{2}\right)\left(T_{\frac{N}{2}}+T_{N+\frac{2}{2}}\right), \text { if } n \text { is even }
\end{array}\right.
$$

$\mathrm{L}$

A positive value of $\mathrm{L}$ indicates an increasing (upward) trend whereas a negative value indicates a decreasing (downward) trend in the time series. Here, R-software is used in estimating the Sen's slope and performing the non parametric Mann-Kendall test.

\section{RESULTS AND DISCUSSION}

The data used in this study is completely secondary in nature. In this study, we have examined trend of historical rainfall data of two stations of Assam viz. Dhubri and Guwahati for the period of $1979-2014$ by using above mentioned methodology.

Table 4.1: Descriptive Statistics

\begin{tabular}{|l|r|r|}
\hline Period & 1979-2014 & 1979-2014 \\
\hline Station & Dhubri & Guwahati \\
\hline Minimum & 0.00 & 0.00 \\
\hline Maximum & 824.72 & 977.85 \\
\hline Range & 824.72 & 977.85 \\
\hline Mean & 196.63 & 227.65 \\
\hline Median & 103.06 & 166.23 \\
\hline Variance & 44018.73 & 51396.46 \\
\hline Std. Deviation & 209.81 & 226.71 \\
\hline Coefficient of Variation & 106.70 & 99.58 \\
\hline $1^{\text {st }}$ quartile & 15.923 & 16.87 \\
\hline $3^{\text {rd }}$ quartile & 355.150 & 390.93 \\
\hline
\end{tabular}

Table 4.1 shows some of the descriptive statistics of Dhubri and Guwahati station. For both the stations Dhubri and Guwahati, the minimum precipitation value is zero; however the mean rainfall is 196.63 and 227.65 respectively throughout the years. Coefficient of variation witnessed more variability in rainfall pattern in case of Dhubri (106.7012) to Guwahati (99.5848).

Table 4.2: Monthly rainfall trends in Dhubri

\begin{tabular}{|c|c|c|c|c|c|}
\hline Months & $1979-2014$ & $1979-1987$ & $1988-1996$ & $1997-2005$ & $2006-2014$ \\
\hline Jan & -0.0852 & -0.2921 & 2.7955 & 1.6775 & 0.7088 \\
\hline Feb & -0.2333 & -0.0059 & -2.7954 & 0.1165 & 2.4018 \\
\hline Mar & -0.2846 & 1.676 & -2.4777 & 3.0282 & 0.6586 \\
\hline Apr & 0.0523 & 4.0604 & -4.2426 & 0.4575 & 3.903 \\
\hline May & -1.3003 & 4.1814 & -11.1603 & -3.5443 & -2.904 \\
\hline Jun & -0.8105 & 19.3451 & 0.6176 & -16.9911 & 0.5994 \\
\hline July & $\mathbf{- 8 . 2 3 5 6}$ & 15.8769 & 3.0598 & 7.724 & 15.1477 \\
\hline Aug & -0.9246 & -3.5306 & 3.7527 & $\mathbf{- 3 7 . 8 3 3 1}$ & 14.1788 \\
\hline Sep & $-\mathbf{3 . 0 6 8 2}$ & 18.9085 & -6.8054 & $\mathbf{- 1 7 . 0 4 9 7}$ & -3.3548 \\
\hline Oct & 0.0275 & 9.4 & 3.3345 & $\mathbf{1 9 . 8 4 1 8}$ & 1.3857 \\
\hline Nov & -0.0876 & 0.3775 & -0.7993 & -0.8813 & -1.1816 \\
\hline Dec & -0.1053 & -1.8218 & -0.2335 & -0.0079 & 0.0806 \\
\hline
\end{tabular}


N.B. Values rendered in bold indicate statistical significance at $95 \%$ confidence level according to the Mann-Kendall Test

The magnitude of the trend of Dhubri district as determined by using the Sen's slope method is given in Table 4.2 and Table 4.3. In Table 4.2, it is observed that the rainfall has gradually decreased in all the months during the period 1979-2014, except for the months of April and October. Further, among the four subdivisions (nine years each) of the entire period, the month of August experienced maximum decrease in rainfall that is during 1997-2005, whereas the month of October witnessed the maximum increase. From Table 4.3, it has been found that for the entire period of 1979-2014 rainfall has gradually decreased during all the four seasons.

Moreover, in Table 4.2, by applying Mann-Kendall test, it is observed that the significant downward trend is shown during the months of July and September for the entire period of 1979- 2014. Further, for the subdivided period 1997-2005, the months of august and September experienced significant downward trend whereas October experienced an upward trend. Also, Table 4.3 witnessed significant downward trend for winter and monsoon months for the entire period of 1979-2014.

Table 4.3: Season wise trend of Dhubri

\begin{tabular}{|l|l|l|l|l|l|}
\hline Season & $1979-2014$ & $1979-87$ & $1988-96$ & $1997-2005$ & $2006-14$ \\
\hline Winter & $\mathbf{- 0 . 0 6 3 5}$ & -0.1977 & 0.0678 & 0.1899 & 0.1705 \\
\hline Pre-Monsoon & -0.0289 & 2.0348 & -0.1296 & 1.4044 & 1.2658 \\
\hline Monsoon & $\mathbf{- 0 . 7 3 7 7}$ & 3.8962 & -1.6674 & -1.0023 & -0.5418 \\
\hline Post-Monsoon & -0.053 & 0.5888 & 0.463 & 0.0865 & -0.6853 \\
\hline
\end{tabular}

N.B. Values rendered in bold indicate statistical significance at $95 \%$ confidence level according to the Mann-Kendall Test

Also, for illustration purpose, we have given only two graphs. In Fig 4.1, we have given significant trend line in the month of July for 1979-2014. Also, we have given significant trend line in the month of July for 1979-2014. Both the graph clearly reflect significant downward trend of historical rainfall data in Dhubri for the period 1979-2014.

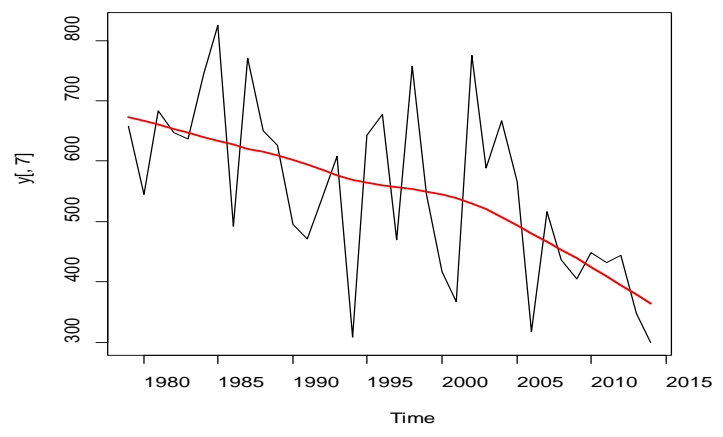

Fig 4.1: Showing the significant downward trend for the month of July for 1979-2014

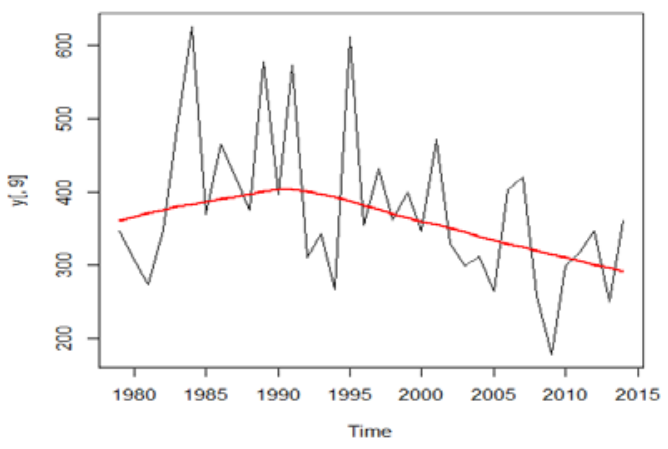

Fig 4.2: Showing the significant downward trend for the month of September, 1979-2014

Similarly, the magnitude of the trend to the historical rainfall data in Guwahati as determined by using the Sen's estimator is given in Table 4.4 and Table 4.5. In Table 4.4, it is observed that the rainfall has gradually decreased during all the months for the entire period of 1979-2014, except for the month of June. Also, among the four subdivisions (9 years each) of the entire period, the month of July experienced maximum decrease in rainfall that is during 2006-2014, whereas April experienced the maximum increase during 1997-2005. From Table 4.5, it is also observed that for the entire period of 1979-2014, rainfall has gradually decreased during all the four seasons in Guwahati.

Table 4.4: Monthly rainfall trends in Guwahati

\begin{tabular}{|c|c|c|c|c|c|}
\hline Months & $1979-2014$ & $1979-87$ & $1988-96$ & $1997-2005$ & $2006-14$ \\
\hline Jan & -0.1856 & 0.2403 & 1.2706 & 0.0886 & 0.0652 \\
\hline Feb & $\mathbf{- 0 . 5 4 5 3}$ & -0.8797 & -1.3914 & -0.3247 & -2.1515 \\
\hline Mar & -0.429 & 4.2696 & 7.1047 & 12.5873 & -0.0571 \\
\hline Apr & -0.5765 & 10.1381 & $\mathbf{- 8 . 5 4 0 3}$ & 24.9521 & -18.7572 \\
\hline May & -1.7108 & -11.8884 & 1.2899 & -3.4096 & -4.8321 \\
\hline Jun & 0.338 & 17.3943 & 7.7992 & -26.2381 & -4.1344 \\
\hline Jul & $\mathbf{- 9 . 3 9 3 9}$ & -5.0518 & -10.5749 & 11.0946 & -36.5004 \\
\hline Aug & -2.4901 & -0.5794 & 4.2551 & -16.3571 & 4.8718 \\
\hline Sep & -2.8792 & 16.9626 & -19.0299 & -3.2872 & 7.1137 \\
\hline
\end{tabular}




\begin{tabular}{|c|c|c|c|c|c|}
\hline Oct & -0.9476 & -0.573 & -11.6008 & 24.7976 & -8.5646 \\
\hline Nov & -0.1551 & 0.9704 & 0.2097 & -1.131 & -1.8806 \\
\hline Dec & $\mathbf{- 0 . 2 9 3 6}$ & -1.5615 & -0.7535 & 0.0386 & -0.0752 \\
\hline
\end{tabular}

N.B. Values rendered in bold indicate statistical significance at $95 \%$ confidence level according to the Mann-Kendall Test.

Moreover, in Table 4.4, by applying Mann-Kendall test, it is observed that a highly significant downward trend of rainfall pattern in Guwahati is observed during the months of
February, July and December for the entire period of 19792014.

Further, for the subdivided period 1988-1996, the months of April experienced a strong significant downward trend in the time series. Moreover, Table 4.5 witnessed significant downward trend for winter and monsoon months for the entire period of 1979-2014

Table 4.5: Season wise trend in Guwahati

\begin{tabular}{|l|l|l|l|l|l|}
\hline Seasons & $1979-2014$ & $1979-87$ & $1988-96$ & $1997-2005$ & $2006-14$ \\
\hline Winter & $\mathbf{- 0 . 0 8 4 2}$ & 0.0149 & 0.075 & 0.0313 & -0.0222 \\
\hline Pre-Monsoon & -0.0686 & 1.6617 & 1.1505 & 5.3256 & -0.8239 \\
\hline Monsoon & $\mathbf{- 0 . 9 6 7 8}$ & 1.4002 & -3.8068 & -4.329 & -1.431 \\
\hline Post-Monsoon & -0.1874 & -0.2792 & -1.8766 & 0.3164 & -1.4123 \\
\hline
\end{tabular}

N.B. Values rendered in bold indicate statistical significance at $95 \%$ confidence level according to the Mann-Kendall Test.

Further, for illustration purpose, In Fig 4.3, we have given significant trend line in the month of February for 19792014. Also, we have given significant trend line in the month of December for 1979-2014. Both the graph clearly reveal significant downward trend of historical rainfall data in Guwahati for the period 1979-2014.

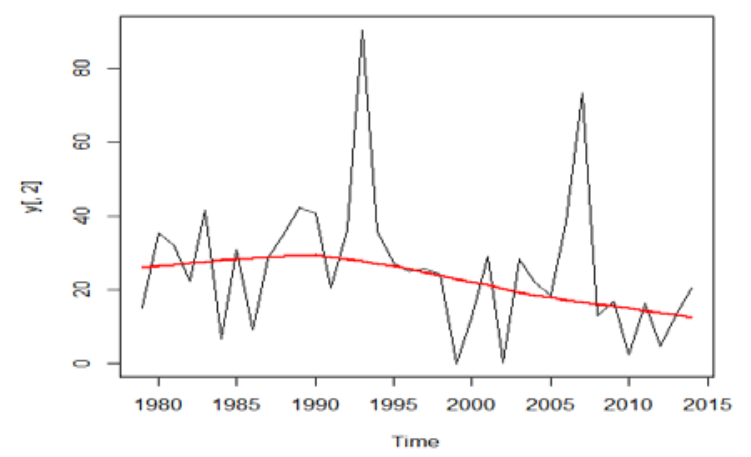

Fig 4.3: Showing the significant downward trend for the month of February during 1979-2014

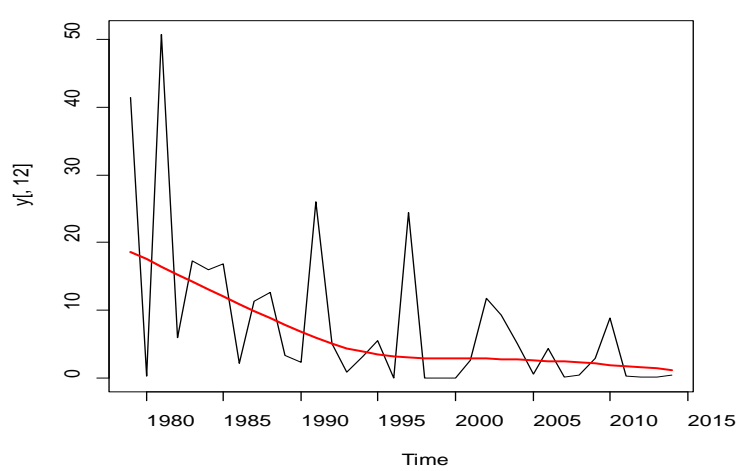

Fig 4.4: Showing the significant downward trend for the month December during 1979-2014

\section{CONCLUSION}

The rainfall characteristics especially variability and trend are necessary for the proper planning and management of water resources. This paper deals with the study of longterm trends of monthly, seasonal and annual rainfall over the two stations of Assam viz. Dhubri and Guwahati, with the length of data series of 36 years (1979-2014). As expected, for both the stations, the monthly analysis of rainfall indicated a gradual decrease in rainfall for the maximum months during the period 1979-2014. Seasonal analysis showed that for the entire period of 1979-2014 rainfall has gradually decreased during all the four seasons. The month of July and September indicated significant downward trend in Dhubri, whereas the month of February, July and December showed the same in Guwahati for the entire period of 36 years. Also, the month of August and September indicated significant decreasing trend and the month of October indicated significant upward trend during the period of 1997-2005 in Dhubri, whereas the month of April during 1988-96 experienced significant downward trend. Moreover, in both the stations, the presence of significant downward trend for winter and monsoon seasons for the entire period of 1979-2014 is being observed.

\section{REFERENCE}

[1] Adler R.F., Huffman G. J., Bolvin D. T., Curtis S. And Nelkin E. J. (2000): “Tropical Rainfall Distributions Determined using TRMM Combined with other Satellite and Gauge Information”, Journal of Applied Meteorology, Vol.39, No 12, pp. 2007-2023.

[2] Adler RF, Huffman GJ, Chang A, Ferraro R, Xie P, Janowiak J, Rudolf B, Schneider U, Curtis S, Bolvin D, Gruber A, Susskind J, Arkin P. (2003): “The Version 2 Global Precipitation Climatology Project (GPCP) Monthly Precipitation Analysis (1979-Present)”, Journal of Hydrometeorology, Vol.4, pp.1147-1167.

[3] Agarwal P.K. (2007): "Climate Change: Implications for Indian agriculture”, Jalvigyan Sameeksha, Vol.22, pp.37-46.

[4] Deka R. L., Mahanta C., Nath K. K. And Dutta M. K. (2015): "Spatio- temporal Variability of Rainfall Regime in the Brahmaputra valley of North East India”, Theoretical and Applied Climatology, DOI 10.1007/s 007 04-015-1452-8. 
[5] Duhan D. and Pandey A. (2013): “Statistical Analysis of Long Term Spatial and Temporal Trends of Precipitation during 1901-2002 at Madhya Pradesh, India”, Atmospheric Research, Vol.122, pp.136-149.

[6] Ganguli A., Chaudhuri R. A. and Sharma P. (2015): “Analysis of Trend of Precipitation Data: A Case Study of Kangra District, Himachal Pradesh”, International Journal of Research Granthaalayah, Vol.3, Issue: 9, pp. 87-95.

[7] Goswami B. N., Venugopal V., Sengupta, D., Madhusoodanan, M.S., Xavier P. K., (2006): "Increasing Trend of Extreme Rain Events over India in a Warming Environment”, Science, Vol. 314, pp.1442-1444.

[8] Goswami K., Patowary A. N. and Hazarika, J. (2017): Studying Nature of the Trends in Some Hydroclimatic Variables Using NP Methods, International Journal of Agricultural and Statistical Sciences, Vol. 13, No.1, pp.205211.

[9] Hamed K. H. and Rao A. R. (1998): "A Modified MannKendall Trend Test for Autocorrelated Data”, Journal of Hydrology, Vol.204, pp.182-196.
[10] Hazarika J., Pathak B. and Patowary A. N. (2017): “Studying Monthly Rainfall over Dibrugarh, Assam: Use of SARIMA Approach”, Mausam, Vol.68, No.2, pp.349-356.

[11] Huffman G. J., Adler R. F., Arkin P., Chang A., Ferraro R., Gruber A., Janowiak J., McNab A., Rudollf B. and Schneider U. (1997): "The Global Precipitation Climatology Project (GPCP) Combined Precipitation Datasets", Bulletin of the American Meteorological Society, Vol.78, No.1, pp.5-20.

[12] Jain, S.K. and Kumar, V. (2012): "Trend Analysis of Rainfall and Temperature Data for India”, Current Science, Vol.2, No.1, pp. 37-49.

[13] Nyatuame M., Owusu-Gyimah V. and Ampiaw F. (2014): "Statistical Analysis of Rainfall Trend for Volta Region in Ghana”, International Journal of Atmospheric Sciences, Vol.2014, 11 pages.

[14] Yue S., Pilon P. and Cavdias G. (2002): "Power of the MannKendall and Spearman rho Test for detecting Monotonic Trends in Hydrological Series”, Journal of Hydrology, Vol.259, pp. 254-271. 